\title{
Z-SOURCE INVERTER FOR PV BASED GRID CONNECTED SYSTEM
}

\author{
Monali P. Samarth \\ Assistant Professor \\ Ramdeobaba College of Engineering and Management, Nagpur, India \\ \{samarthmonali@gmail.com\}
}

\begin{abstract}
Now a day's distribution generation (DG) systems are increasingly used to feed power to the grid. Different DG sources generate power at different voltage levels and with different frequencies. Thus, it becomes important to rise the voltage levels and maintain the frequency as desired by the grid to be supplied. Instead of using traditional buck- boost converter we can use Z-source inverter which overcomes the drawbacks of traditional converters. The shoot through state of Z-source inverter (ZSI) is responsible for providing buck or boost feature at the output of inverter. MPPT is used to provide maximum power at any environmental condition and is utilized for inserting the shoot through state in ZSI. The main objective is to feed good quality of power to the grid. For this concern, an effective controller has been designed to feed power to the grid with less unbalance and less THD which are of prime importance. This paper presents a three level Z-source inverter supplied by PV source as a DC input. The effective controller design for harmonic elimination and synchronization of grid frequency with inverter frequency is carried out using MATLAB software and simulation studies are presented.
\end{abstract}

Keywords: Z-source inverter; MPPT; Grid Connection;

\section{Introduction}

Renewable energy sources are of great interest for DG systems. The DG's are recently investigated to feed power to the grid. Nonlinear load connected to the grid deteriorate the power quality of the grid and causes various power quality problem. Among these power quality problems harmonics and unbalance are of main concern. The multilevel inverter is used to feed power to the grid with minimum THD and unbalance. Instead of utilizing the traditional inverters for boosting the DG voltage, $\mathrm{Z}$ source inverter can be used. The $\mathrm{Z}$ source inverter [1-3], overcomes the following drawbacks of traditional converter.

Problems found in traditional converters are as follows

- They operate in either boost mode (CSC) or buck mode (VSC), not in buck-boost mode.

- Misgating of switches may cause shoot through in a VSC or may cause an open inductor circuit in CSC, which can destroy the switches.

- Dead time for VSC and overlap time for CSC can cause waveform distortion.

- The power circuit topology of VSC and CSC are not interchanged, that is VSC main circuit cannot be used for CSC or vice-versa.

The Z-source inverter [4] has unique shoot through state which is responsible for providing buck or boost feature to the inverter. No dead time is required for safe commutation in ZSI. Whenever renewable energy source is used as a DC input, MPPT is necessary to provide maximum power at any environmental conditions. The PV characteristics have complex relationship with the irradiance and with the temperature. 


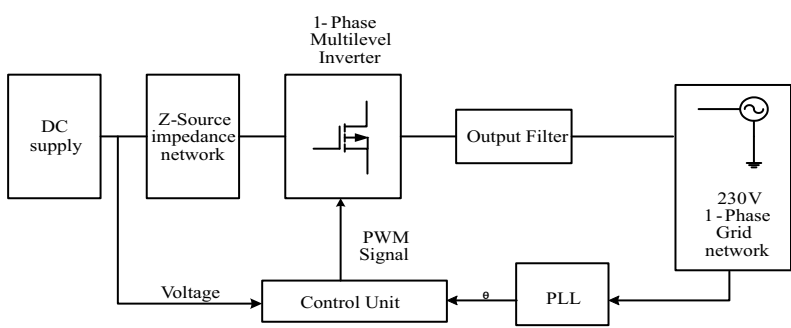

Fig. 1 : Blocked Diagram of Proposed System

The PV characteristics get affected with the change in irradiance and temperature. The Perturb and Observe ( $\mathrm{P} \& \mathrm{O})$ method is used to track the maximum power at given environmental conditions. Here, MPPT is also used to provide shoot through state in ZSI. Synchronisation of grid is an important issue and thus Phase locked loop (PLL) has been used. PLL generates the fundamental output voltage which is then applied to the closed loop controller, thus the grid frequency is synchronised with the inverter frequency. Power feed to the grid must be at unity power factor and with less distortion. For this a closed loop controller is designed which incorporates the action of voltage controller and current controller. The switching of the inverter is dependent on the grid voltage and grid current whereas the shoot through state for providing the boost is carried out using MPPT. The parameter design of Z-source inverter plays an important role for providing maximum boost to the inverter. Section II explains Z-Source inverter. Section III explains the control strategy and Section IV presents the simulation. Section V summarises the result.

\section{Z-Source Inverter}

The Z-source inverter (ZSI) topology used in power conversion has unique features that can overcome the limitations of VSI and CSI. Fig 2 shows the structure of Z-source converter. Although DC/AC conversion is the most common application of the Z-source topology, it can also be applied for power conversions involving $\mathrm{AC} / \mathrm{DC}$ and $\mathrm{AC} / \mathrm{AC}$ applications. The $\mathrm{X}$ shape impedance is the Z-source impedance network comprises of two split inductors and two capacitors to provide a coupling between the DC source and the inverter bridge.

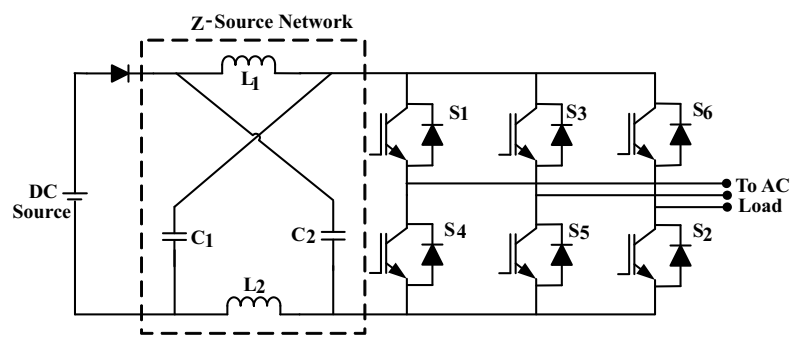

Fig. 2 : Three phase Z-source Inverter

The Z-source inverter (ZSI) has the unique buck-boost capability which provides an output voltage range from zero to infinity regardless of the input voltage. This output voltage range is obtained with an unique switching state, termed as "shoot-through" state. This state is obtained when both upper and lower switches of the same phase leg are turned on. In a conventional VSI switching pattern, the permissible switching states are eight. The six switching states where the load sees the input voltage are called the "active" states and the remaining two states where either all the upper or all the lower switches are on and the load sees zero voltage are called the "zero" states. The output voltage of inverter can be given as

$$
\begin{gathered}
V_{i}=V \sin \theta \\
M=\frac{V}{V_{d c}} \\
D=\frac{1-M \sin \theta}{2-M \sin \theta}
\end{gathered}
$$

Where $M$ is the modulation index and $\varnothing$ the output voltage angle.

The Z-source inverter [5-7] has two operating modes: Shoot through mode and Non shoot through mode. Fig 3 shows the equivalent circuit of ZSI at non shoot through mode. In this mode the inverter is in one of the six active states. The diode gets forward biased and load is supplied. 


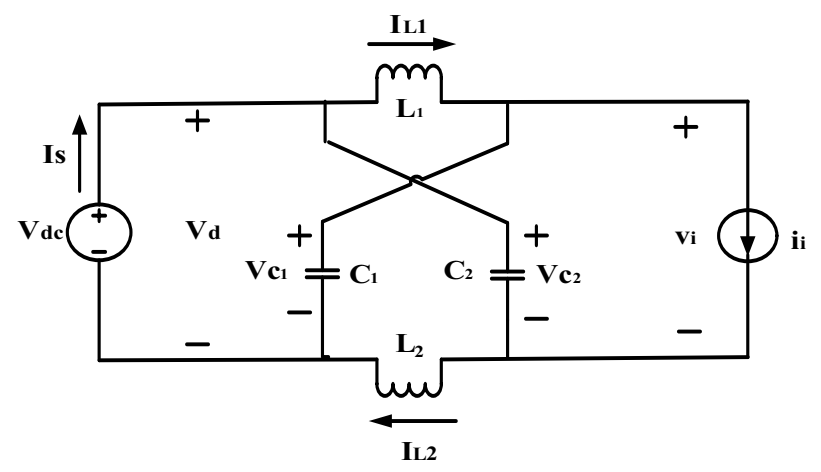

Fig. 3 : Non Shoot Through Mode

Assume the Z-source inductors $\left(L_{1} \& L_{2}\right) \&$ capacitors $\left(C_{1} \& C_{2}\right)$ respectively. From the equivalent circuit, we have because of symmetry.

$$
V_{L 1}=V_{L 2}=V_{L}, \quad V_{C 1}=V_{C 2}=V_{C}
$$

When the ZSC is in the non-shoot through state for a period $T_{1}$. From Fig. 3, the inductor voltage and output voltage of the inverter are expressed as

$$
V_{L}=V_{d c}-V_{C}, \quad V_{i}=V_{C}-V_{L}=2 V_{C}-V_{d c}
$$

When two switches of any three phase legs are made on at the same time, the circuit enters the shoot through state, where sum of the two capacitors voltage is greater than the dc source voltage $\left(V_{C l}+V_{C 2}>V_{d c}\right)$ the capacitors charge the inductors with $\mathrm{t}_{1 \mathrm{~L}}\left(V_{\mathrm{Cl}}+V_{\mathrm{Cl}_{2}}>V_{d d}\right)$, in reverse biased condition. The voltages across the inductors are

$$
V_{L 1}=V_{C 1}=V_{L 2}=V_{C 2}
$$

The average voltage of an inductor over a complete period $\mathrm{T}$ is zero in steady state, the capacitor voltage can be derived as

$$
V_{C}=\frac{T_{1}}{T_{1}-T_{s h}} V_{d c}=\frac{1-D}{1-2 D} V_{d c}
$$

Where $T=T_{1}+T_{s h}$ is the switching period \& $D=T_{s h} / T$ is the shoot through time duty ratio.

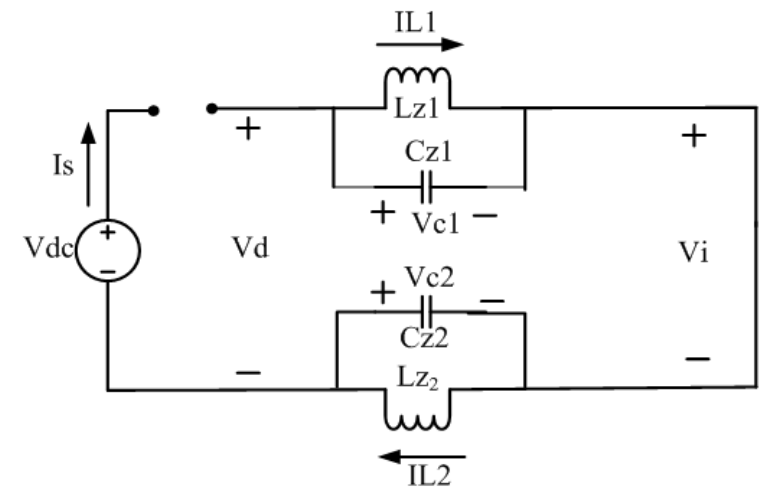

Fig. 4 : Shoot Through Mode
$\mathrm{V}_{\mathrm{c}}$ is the steady state $(\mathrm{dc})$ value of capacitor voltage \& $\mathrm{V}_{\mathrm{dc}}$ the steady state value of the input voltage. Similarly output voltage $\mathrm{V}_{\mathrm{i}}$ can be derived as

$$
V_{i}=\frac{1-D}{1-2 D} V_{d c}
$$

As equation (7) and (8) has equal right hand side hence left hand side should be same. Hence

$$
\begin{aligned}
& \mathrm{V}_{\mathrm{i}}=\mathrm{V}_{\mathrm{c}} \\
& \mathrm{D}=1-M
\end{aligned}
$$

Where $M$ is the modulation index, the boost factor $B$ can also be derived as

$$
B=\frac{1}{1-2 D} \geq 1
$$

From equation (7) \& (8) boost factor can be given as

$$
B=\frac{1}{2 M-1}
$$

In $\mathrm{Z}$ source network values of inductor and capacitor play a very important role [8]. The voltage boost required depends on shoot through time period but it is also dependent on the rating of capacitor and inductor, if values of $\mathrm{Z}$ source network is not calculated properly then the required amount of boost will not be obtained at output side and causes adverse effects in terms of ripples.

The sinusoidal pulse width modulation techniques which are carrier based, like IPD, APOD, POD and phase shift pulse width modulation can be used for Z-source inverter. To provide shoot through state in the ZSI different boosting techniques [9] is studied. The different boosting techniques are the simple boost control, the maximum boost control, the $3^{\text {rd }}$ harmonic injected constant boost control and the $3^{\text {rd }}$ harmonic injected maximum boost control method. For providing shoot through state in the ZSI simple boost control technique is used with phase shift PWM as shown in Fig 6. 


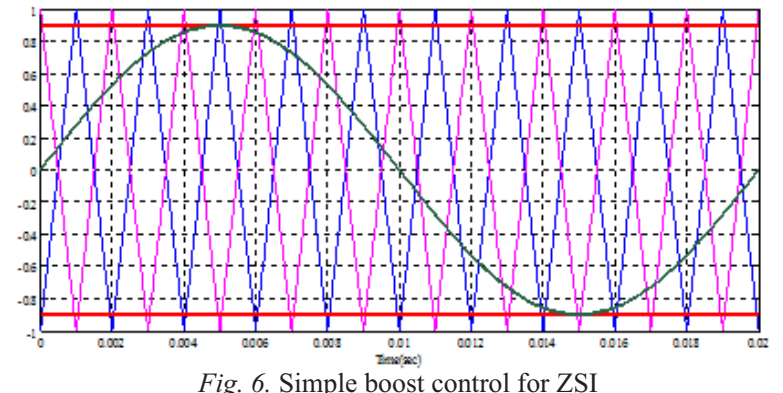

As shown in Fig 6 the Sinusoidal PWM (SPWM) is generated by comparing carrier triangular wave with reference sine wave. For generation of shoot through pulses, the carrier wave is compared with two complementary DC reference levels. For realization of shoot through duty ratio (D), two envelopes with constant magnitude are employed. The first envelope is equal to the peak value of the sinusoidal reference voltages while the other one is the negative of the first one. Whenever the triangular carrier wave is higher than or lower than the positive and negative envelope the inverter will operate in shoot-through mode whereas it operates as traditional inverter.

\section{CONTROL STRATEGY}

To feed good quality of power to the grid the control strategy is carried out as shown in following Fig 7.

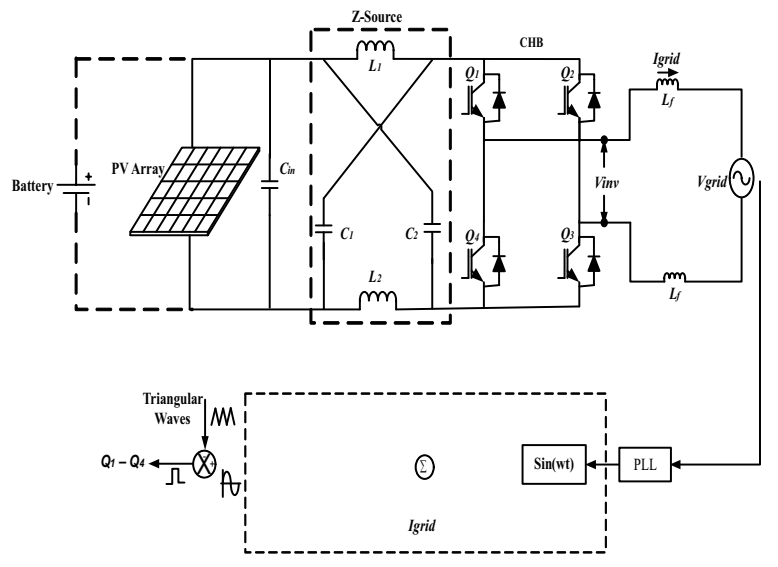

Fig. 7 : Circuit Diagram of Z-Source Inverter based Grid Connected System

The circuit diagram for Z-Source based grid connected system is shown in Fig 7. Here PV module is used as a DC input. As we know that PV voltage is not much sufficient to feed power to the grid, the Z-source impedance network is connected at the output of PV. A three level cascaded H-bridge inverter is used to feed AC power to the grid. The Z-Source inverter is connected to the grid through the interface inductor. The interface inductor is used to reduce the harmonics in the grid current.

$$
L_{f}=\frac{V_{d c} \times D \times(1-D)}{f_{s w} \times \Delta I_{L \max }}
$$

Where $\mathrm{V}_{\mathrm{dc}}$ is the $\mathrm{DC}$ voltage of the inverter, $\mathrm{f}_{\mathrm{sw}}$ is switching frequency of the inductor; $D$ is the duty cycle and $\Delta \mathrm{I}_{\mathrm{Lmax}}$ is ripple current of the inductor.

For synchronization of inverter frequency with grid frequency, a closed loop controller is designed [10], which is also responsible for firing switches of inverter. In this control unit the phase locked loop (PLL) block is utilized to synchronize inverter frequency with the grid frequency. The $I_{\text {ref }}$ is then multiplied with fundamental grid voltage and the resultant obtained is then compared with the grid voltage. The sine wave obtained from the control unit is then compared with the triangular carrier wave to obtain the pulses. For providing boost to the inverter shoot through state is necessary, this shoot through state is generated by using maximum power point tracking (MPPT) method [11]. The Perturb and observe (P\&O) method of maximum power point tracking is used in this work. The Perturb and observe method, will track the maximum power at any environmental condition and gives the maximum power at the output of PV. Here the Perturb and observe method is also used to provide shoot through state for providing the maximum boost to the inverter [11].

Perturb \& Observe $(\mathrm{P} \& \mathrm{O})$ is the simplest method of tracking MPP. The time complexity of this algorithm is very less. Only voltage sensor is utilized to sense the PV array voltage and so the cost of implementation is less and hence easy to implement. It keeps on perturbing in both the directions. When this happens the algorithm reaches the MPP and we can set an appropriate error limit. In this method the controller adjusts the voltage in lesser amounts from the array and measures power; if the power continues to increase then further adjustments are carried out in that direction and is continued till there is not an increase in power, which Vol. 01, Issue 02, April 2016 
eventually leads to maximum point. This is called a 'Perturb and Observe' method.

\section{Simulation Results}

MATLAB SIMULINK has simulated the proposed system for different irradiance levels. The main objective is to feed good quality of power to the grid. For this the grid current must have fewer harmonic and must be in phase with the grid voltage. To inject current to the grid the output voltage of inverter must be greater than

$\left(\sqrt{ } 2 \mathrm{~V}_{\text {grid }} \mathrm{V}_{\text {grid }} \mathrm{V}=230\right)$

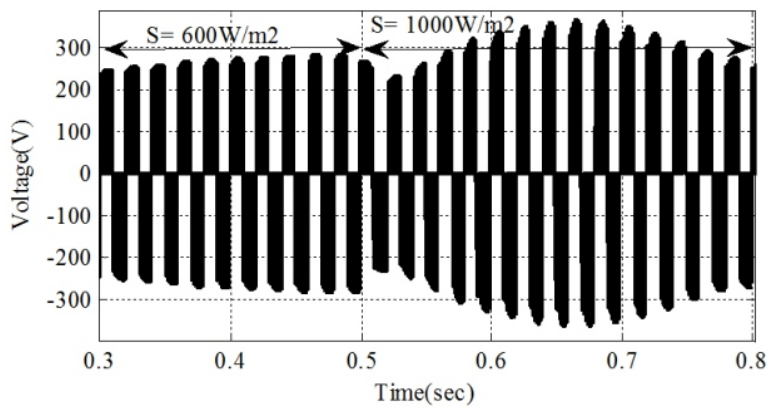

Fig. 8. Output Voltage of Cascaded Three Level Inverter with change in irradiance

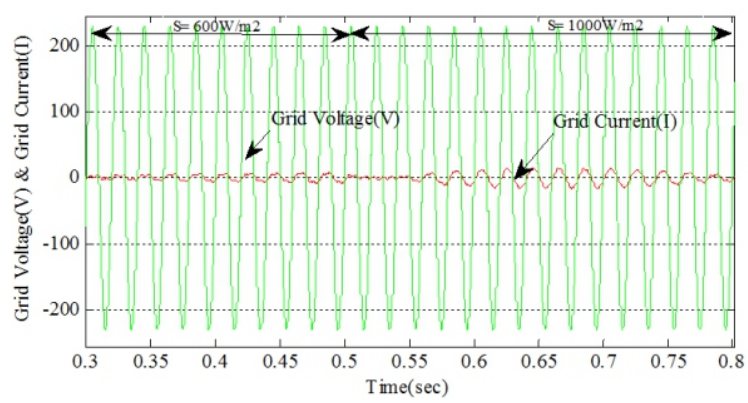

Fig. 9. Waveform of Grid Current \& Grid Voltage

For $600 \mathrm{~W} / \mathrm{m}^{2}$ irradiance the output of inverter is less than $326 \mathrm{~V}$, hence the current fed in to the grid is distorted as shown in Fig. 9. As the irradiance level increases from $600 \mathrm{~W} / \mathrm{m}^{2}$ to $1000 \mathrm{~W} / \mathrm{m}^{2}$ the current fed to the grid also get fine with reduced harmonics as shown in Fig. 9 because input to the inverter is greater than 326 $\mathrm{V}$. The transients of 0.1 second are present during change in irradiance.

For irradiance $\mathrm{S}=600 \mathrm{~W} / \mathrm{m}^{2}$

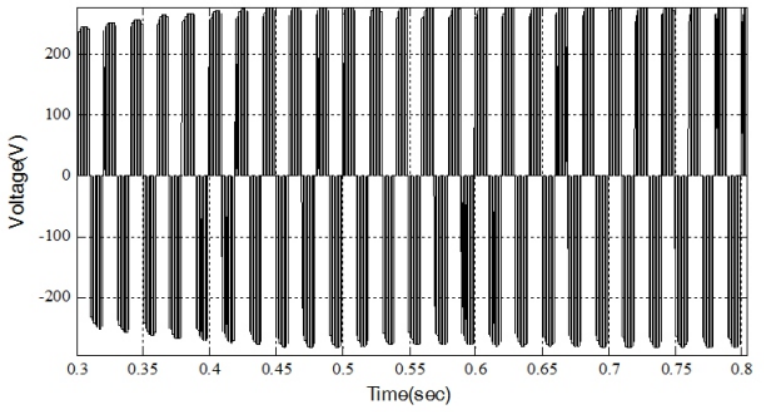

(a)

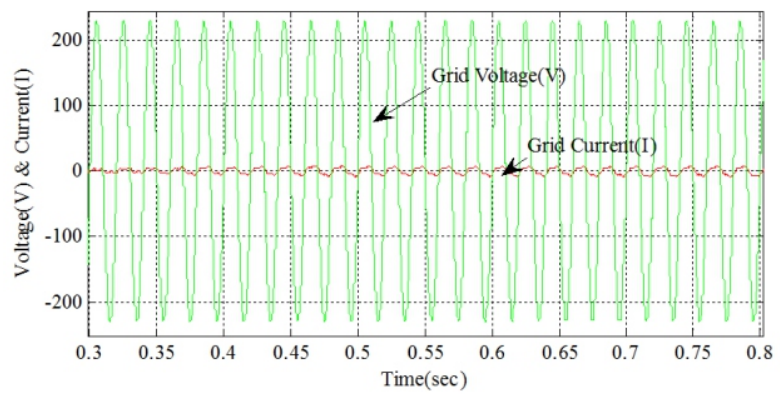

(b)

Fig.10 (a) Three level output voltage of inverter (b) In-phase waveform of Grid Voltage and Grid Current (c) Active Power $\&$ Reactive Power fed to the Grid

The Z-source will boost the voltage of PV. Fig 10(a) shows the boosted output of inverter for irradiance of $600 \mathrm{~W} / \mathrm{m}^{2}$. Fig $10(\mathrm{~b})$ shows the waveform of grid voltage and grid current which are in phase with each other but it is distorted for less irradiance because the output of inverter is not greater than $326 \mathrm{~V}$. The magnitude of grid current is also less for less irradiance hence power fed to the grid is also less. Fig 10(c) shows the active and reactive power waveform. From Fig 10(c) it is clear that power fed to the grid is $550 \mathrm{~W}$ for irradiance of $600 \mathrm{~W} / \mathrm{m}^{2}$.

For irradiance $\mathrm{S}=1000 \mathrm{~W} / \mathrm{m}^{2}$

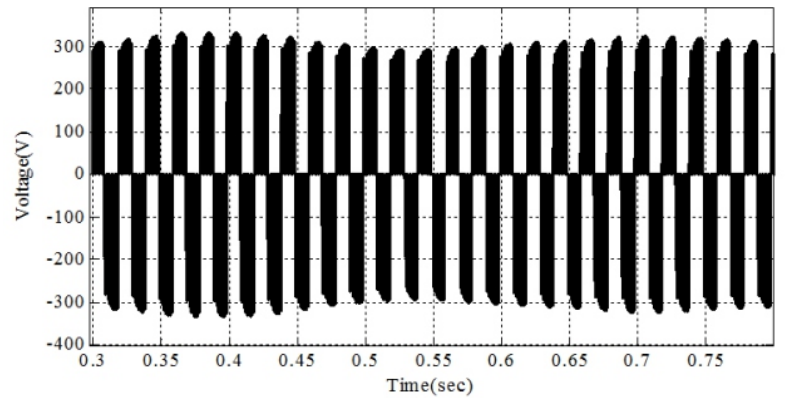

(a) 


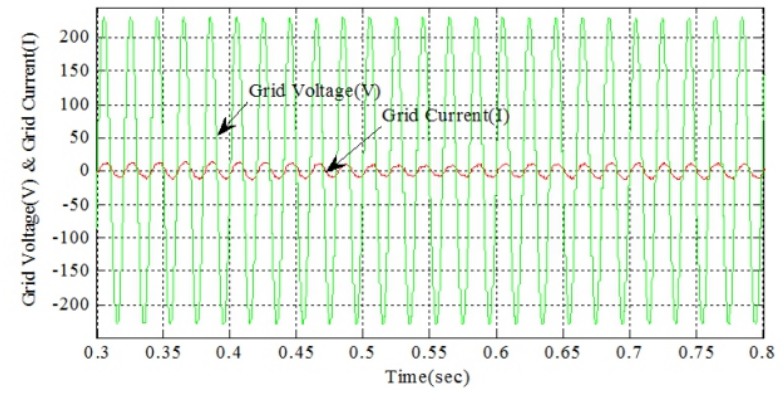

(b)

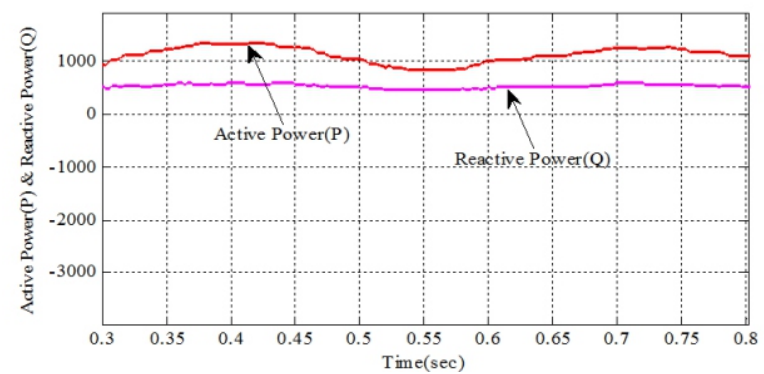

(c)

Fig. 11 : (a) Three level output voltage of inverter (b)Inphase waveform of Grid Voltage and Grid Current (c) Active Power $\&$ Reactive Power fed to the Grid

For more irradiance of $1000 \mathrm{~W} / \mathrm{m}^{2}$ the boosted output of inverter is shown in Fig 11(a). The grid current for high irradiance is shown in Fig 11(b). The power fed to the grid for irradiance of $1000 \mathrm{~W} / \mathrm{m}^{2}$ is greater because there is increase in grid current. Fig 11(c) shows the active power and reactive power fed to the grid. It shows that as the irradiance increases, harmonics in grid current decreases. The Z-source impedance network also increases the harmonics due to the presence of passive component. Hence, effective controller strategy can be implemented to reduce harmonics and to feed good quality of power to the grid. Also with the increase in number of levels at the output of inverter we can reduce the harmonics in the grid current.

\section{Conclusion}

This paper presents the design and simulation of Z-source inverter for the grid connected system. The Z-source dc ac inverter (ZSI) is a recent power conversion topology that is very promising in power conditioning of alternative energy sources and applications like photovoltaic application, HEVs and utility interfacing, adjustable speed drive, fuel cell.
Based on the circuit analysis, the Z-Source inverter can be implemented with the MPPT using voltage and current control for injecting current to the grid with good power factor and grid synchronization. The effect of Z-source is in term of increasing the harmonics with higher boost. But effective controller strategy can be implemented to minimize the harmonics and fed maximum active power to the grid for such systems. Such system can be used for standalone PV based system in upcoming recent smart metering technologies where an individual customer can fed power to the grid/microgrid.

\section{References}

[1] M. Calais and V. G. Agelidis, "Multilevel converters for single-phase grid connected photovoltaicsystems - An overview," Proc. IEEE Int. Symp. Ind. Electron., vol. 1, pp. 224-229, 1998.

[2] S. B. Kjaer, J. K. Pedersen, and F. Blaabjerg, "A review of single-phase grid connected inverters for photovoltaic modules," IEEE Trans. Ind. Appl., vol. 41, no. 5, pp.1292-1306, Sep./Oct. 2005.

[3] Minsoo Jang, Mihai Ciobotaruand Vassilios G. Agelidis "A Single-Phase Grid-Connected Fuel Cell System Based on a Boost-Inverter," IEEE Trans. Power Electronics, vol. 28, Iss. 1, pp. 279-288, Jan 2013.

[4] F. Z. Peng, "Z-source inverter," IEEE Trans. Ind. Appl., vol. 39, no. 2, pp. 504-510, Mar./Apr. 2003.

[5] Yu Tang, ShaojunXie and Chaohua Zhang, "Single-Phase Z-Source Inverter," IEEE Trans Power Electron., vol. 26, no. 12, pp. 3869-3873, Dec 2011. 
[6] Po Xu, Xing Zhang, Chong-wei Zhang, Ren-xian Cao, and Liuchen Chang, "Study of Z-source inverter for grid connected PV systems," IEEE PESC, pp.18-22, June 2006.

[7] Poh Chiang Loh, D. Mahinda Vilathgamuwa, YueSen Lai, Geok Tin Chua, and Yunwei Li, "Pulse-Width Modulation of Z-Source Inverters," IEEE Trans Power Electron., vol. 20, no. 6, pp. 1346-1355, Nov 2005.

[8] Sumedha Rajakaruna, Laksumana Jayawickrama, "Steady-State Analysis and Designing Impedance Network of Z Source Inverters," IEEE Trans. Ind. Electron., vol. 57, Iss. 7, pp. 24832491, July 2010.

[9] MiaosenShen, Jin Wang, Member, Alan Joseph, Fang ZhegPeng, Leon $\mathrm{M}$. Tolbert, and Donald J.Adams, "Constant Boost Control of the Z- Source Inverter to Minimize Current Ripple and Voltage Stress", IEEE Trans. Ind. Appl., vol. 42, no. 3, pp 770-777, May/June 2006.
[10] Hongbin Wu, Hui Sun, Liang Cai, Xiaofeng Tao, "Simulation on Control Strategies of Grid-connected Inverters," IEEE int. symp. power electron. distributed generation system., pp. 904908,2010 .

[11] M.L. Florea, A. Baltatanu," Modeling Photovoltaic Arrays with MPPT Perturb \& Observe Algorithm", Int. Symp. Advanced topics in Electrical Engg., pp. 1-4, May 2013.

[12] Babak Farhangi, and Shahrokh Farhangi, "Application of Z-source converter in photovoltaic grid-connected transformer-less inverter, "Electrical Power Quality and Utilization, Journal, vol. 7, no. 2,pp. 41-45, 2006. 